\title{
Biosimilar monoclonal antibodies
} —challenges and opportunities in Europe

\author{
Professor Andrea Laslop, MD
}

\section{New regulations for the development of biosimilars have been introduced in Europe and a new class of biosimilars - mono- clonal antibodies - is expected on the market soon, which will both challenge and benefit our healthcare systems.}

Keywords: Biosimilars, comparability, extrapolation, monoclonal antibodies, switching

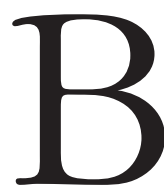

iosimilars are biological medicinal products, which contain a version of the active substance of an already authorized original biological medicinal product [1]. Once the market exclusivity period of the innovator has expired, biosimilars can be approved as copy versions of the originator product according to a specific abridged marketing authorization procedure, which demands the demonstration of similarity in physicochemical characteristics, efficacy and safety, based on a comprehensive comparability exercise. In most cases, biosimilars are manufactured from a separate production line, often by a different company and sometimes using a different expression system.

Consequently, although conditions and operations of production are chosen to be as closely related to the originator's process as possible, it is clear that no exactly identical copy can be made due to the complex nature of the biological product, and some differences are inevitable. This situation, and the fact that biological products generally have a more complex structure than chemically synthesized substances, calls for regulatory approval and life cycle management that differs from the current approval process for generics.

The EU regulatory system has therefore developed a specific framework of guidelines and standards for the approval and pharmacovigilance of biosimilars. This framework has been laid down in Directive
2001/83/EC [2] and subsequently extended in a growing number of guidelines and authorized products on the market (published on the European Medicines Agency [EMA] website) [3]. Generics are usually approved on the basis of demonstration of bioequivalence with the originator reference product, but a more comprehensive development programme is needed for biosimilars. This involves extensive comparability studies at the level of quality characteristics, biological activity and functional characterization. Non-clinical and clinical data are also needed, normally not only including a comparison of pharmacokinetic (PK) and pharmacodynamic (PD) characteristics, but also requiring the demonstration of equivalence in efficacy and comparable safety between the biosimilar and the biological reference product. Details of the studies and data required for marketing authorization are addressed in the EMA guidelines on quality issues and on non-clinical and clinical issues relating to biosimilars, both of which are currently under revision [4, 5], as well as in further product specific biosimilar guidelines [3]. In specific cases, where there is a reliable and validated surrogate PD parameter for demonstration of efficacy, approval can be accepted on the basis of clinical data limited to similarity in PK and PD as well as safety.

In June 2012, the European Commission signalled a change in its position on the use of the reference medicinal product in the comparability exercise [6]. The previous requirement of exclusively using a reference

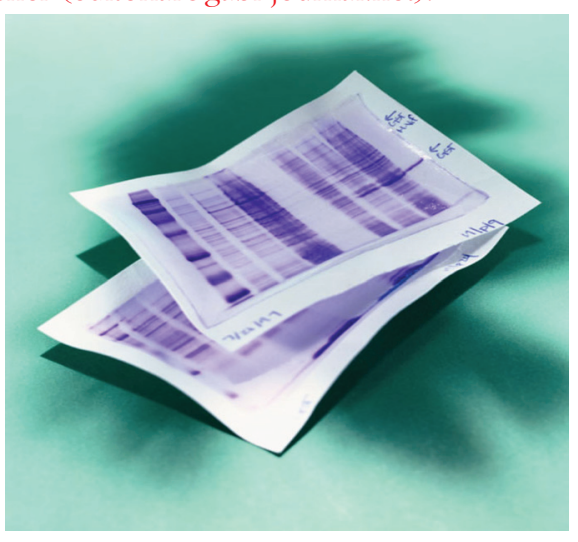

product that had been licensed in the European Economic Area (EEA) has created a significant obstacle to companies pursuing global development. Recognizing these difficulties, EU regulators will now accept pivotal data from comparisons of the new biosimilar product with reference products authorized in regulated markets outside EEA, provided that certain preconditions are met. It is the applicant's responsibility to establish the bridge from the non-EU to the EU reference product and to demonstrate that the former is representative of the latter. This can be achieved with an additional comparison between the non-EU and the EU reference product, encompassing a thorough comparative assessment at the physicochemical and functional level and, depending on the results, clinical data on the PK and PD profile of both originators. A corresponding wording has been introduced in the revision of the guideline on similar biological medicinal products [1], which was released by EMA on 26 April 2013 for public consultation.

By following the stepwise approach for demonstration of biosimilarity, some differences are already expected at the analytical step of physicochemical and functional comparison. These differences, however minor, may extend into the non-clinical and clinical studies and the challenge is to decide whether they bear clinical relevance. Although current methods for analyzing the structural similarity between originator and biosimilar are extremely refined and sensitive, it is very difficult or almost impossible to determine the clinical consequences of differences based on structural information only. On the other hand, the clinical comparability exercise is the least sensitive method for detecting differences. Even if 
present, disparities may go undetected in a clinical study of limited sample size, especially when the deviation of the biosimilar from the reference product mostly impacts the safety profile with a difference in immunogenicity or other rare adverse events. Thus, it is the totality of data that will deliver the overall picture of comparability and have to be taken into account in order for the regulator to make a well-informed decision with sufficient reassurance that the scientific standards and regulatory requirements defined for the approval of a biosimilar medicine are met.

Until recently, relatively simple biological compounds such as growth hormone, erythropoietin and granulocyte colonystimulating factor (filgrastim) have been successfully brought to the market [7]. Nevertheless, following their approval several years ago it took on average another two to four years until they were accepted by the clinical community and the payers' institutions and subsequently able to penetrate the market $[7,8]$. Now, the considerably more complicated monoclonal antibodies are developed as biosimilars by several different enterprises. The dossier for the first of these, the biosimilar monoclonal antibody infliximab, has been filed to EMA for evaluation and received a positive opinion for marketing authorization by the Committee for Medicinal Products for Human Use (CHMP) in June 2013. The same product was licensed in July 2012 in South Korea as Remsima, and two other 'similar biologics' monoclonal antibodies, Rituxan (rituximab) and Etacept (etanercept), have been approved by the regulatory authorities in India. However, these marketing authorizations were not granted according to the standards as specified in the EU regulation and as such cannot be seen as true biosimilars in the European regulatory sense [9-11].

Apart from the above-mentioned marketing authorization procedure for a biosimilar infliximab, numerous requests for scientific advice related to biosimilar monoclonals have been discussed in the Scientific Advice Working Party, and recommendations for consistent development programmes have been given by CHMP. This indicates significant activity of the biosimilar industry, and several products providing copies of monoclonal antibodies could obtain approval and enter the market in the coming years.

However, there are further obstacles to overcome before this new class of bio- similars could effectively be used in daily clinical practice. Decisions on reimbursement, often referred to as the fourth hurdle, are the next step and could cause a delay in market access. From the payers' side, an objection to the price of biosimilars may be expected. The price of biosimilar monoclonal antibodies is forecast to be $10-30 \%$ less than originators $[7,8]$, which is considered too small for significant savings in healthcare expenditure. Notwithstanding, the replacement of innovator monoclonal antibodies with their respective biosimilar counterparts has been calculated to lead to considerable healthcare cost savings of between Euros 1.8 and 20.4 billion between 2007 and 2020 [8], underlining the importance of biosimilars in preserving the sustainability of our healthcare systems.

Clinicians are reluctant to use, or specifically to switch previously treated patients to, a product they are not sure has been sufficiently tested in patients [12]. This reluctance is all the more likely with biosimilar monoclonal antibodies, where extrapolation between products and between different indications is even more demanding. However, this stance ignores the fact that clinical trials on efficacy and safety comparisons between the biosimilar and the originator have been undertaken, albeit with a smaller sample size than normally expected during development of an innovator product. Several aspects need to be reflected upon and measures taken in order to strengthen this limited set of data. Extrapolation from one indication that has been studied in the clinical comparability exercise to others for which the originator has been previously licensed is more straightforward if the same mechanism of action of the monoclonal antibody is involved. Nevertheless, for some indications, different parts of the monoclonal antibody, e.g. not only Fab fragments, but also Fc $\gamma$ receptor subtypes; may play an innate role in the mode of action and, in these instances, it is particularly relevant to consider additional results from PD comparisons, in a type of fingerprint approach.

As regards the extent of the safety database, the significance of further collection of postmarketing safety data, of prime importance for immunogenicity, is recognized. In line with the new pharmacovigilance legislation, this set of data will strengthen the ongoing evaluation of risks and thus support the conclusion on the benefit-risk balance. Special emphasis is laid on the traceability of either the originator or the biosimilar used in clinical practice so that the rate and severity of adverse events is identified for each product. Interchangeability cannot readily be concluded at the stage of approval due to a potential difference in rare adverse events, especially in the formation of antibodies against the therapeutic proteins. Traceability will only be possible by means of large databases accrued post-marketing from either specific safety studies or real-world data collection. It should be possible to detect any significant difference in immunogenicity reactions or other untoward effects if marketing authorization holders gather these data effectively and clinicians adhere to the requisite for careful documentation of brand names and batches. In this way, the clinical community will be given sufficient reassurance on the safe use of biosimilars with greater acceptance. It remains prudent, however, to avoid multiple switching between originators and biosimilar monoclonal antibodies until more extensive clinical experience is available.

\section{Disclaimer}

The views expressed in this paper are the personal views of the author and may not be understood or quoted as being made on behalf of the Austrian Agency for Health and Food Safety or the Committee for Medicinal Products for Human Use.

\section{Competing interests: None.}

Provenance and peer review: Commissioned; externally peer reviewed.

\section{References}

1. European Medicines Agency. Guideline on similar biological medicinal products, CHMP/437/04 Rev 1. 2013 [homepage on the Internet]. 2013 [cited 2013 Jul 16]. Available from: http://www. ema.europa.eu/docs/en_GB/document_library/ Scientific_guideline/2013/05/WC500142978.pdf

2. Directive $2001 / 83$ /EC of the European Parliament and of the Council of 6 November 2001 on the Community code relating to medicinal products for human use (OJL311, 28.11.2001, p. 67) [homepage on the Internet]. 2012 [cited 2013 Jul 16]. Available from: http://ec.europa.eu/health/files/ eudralex/vol-1/dir_2001_83/2001_83_ec_en.pdf

3. European Medicines Agency. Multidisciplinary: Biosimilar - list of scientific guidelines on biosimilar medicines [homepage on the Internet]. 2013 [cited 2013 Jul 16]. Available from: http://www. emea.europa.eu/ema/index.jsp?curl=pages/ regulation/general/general_content_000408. jsp\&mid=WC0b01ac058002958c

References 4-12 can be found on page 107. 


\section{Biosimilar monoclonal antibodies - challenges and opportunities in Europe} References (please see the full manuscript on pages 110-111)

4. European Medicines Agency. Guideline on similar biological medicinal products containing biotechnology-derived proteins as active substance: quality issues (revision 1), EMA/CHMP/BWP/247713/2012 [homepage on the Internet]. 2012 [cited 2013 Jul 16]. Available from: http://www.ema.europa.eu/docs/ en_GB/document_library/Scientific_guideline/ 2012/05/WC500127960.pdf

5. European Medicines Agency. Guideline on similar biological medicinal products containing biotechnology-derived proteins as active substance: non-clinical and clinical issues, EMEA/CHMP/ BMWP/42832/2005. 22 Feb 2006 [homepage on the Internet]. 2012 [cited 2013 Jul 16]. Available from: http://www.ema.europa.eu/docs/en_GB/ document_library/Scientific_guideline/2009/09/ WC500003920.pdf

6. European Medicines Agency. European Medicines Agency to accept biosimilar reference medicines sourced outside European Economic Area. 28 Sep 2012 [homepage on the Internet]. 2013 [cited 2013 Jul 16]. Available from: http://www.emea.europa.eu/ema/index. jsp?curl=pages/news_and_events/news / 2012/09/news_detail_001615.jsp\&mid= WC0b01ac058004d5c1

7. De Labry AO, Gimenez E, Lindner L, Garcia L, Espin J, Rovira J. Biosimilars in the European market. Generics and Biosimilars Initiative Journal (GaBI Journal). 2013;2(1):30-5. doi:10.5639/ gabij.2013.0201.012

8. Haustein R, de Millas C, Höer A, Häussler B. Saving money in the European healthcare systems with biosimilars. Generics and Biosimilars Initiative Journal (GaBI Journal). 2012;1(3-4):120-6. doi:10.5639/gabij.2012.0103-4.036

9. Weise M, Bielsky MC, de Smet K, Ehmann F, Ekman N, Narayanan G, et al. Biosimilars-why terminology matters. Nat. Biotechnol. 2011; 29(8):690-3

10. GaBI Online-Generics and Biosimilars Initiative. How are biosimilars special [www.gabionline. net]. Mol, Belgium: Pro Pharma Communications International; [cited 2013 Jul 16]. Available from: www.gabionline.net/Biosimilars/Research/ How-are-biosimilars-special

11. Thorpe R, Wadhwa M. Terminology for biosimilarsa confusing minefield. Generics and Biosimilars Initiative Journal (GaBI Journal). 2012;1(3-4):132-4. doi:10.5639/gabij.2012.0103-4.023

12. Declerck PJ, Simoens S. A European perspective on the market accessibility of biosimilars. Biosimilars. 2012;2:33-40.

DOI: 10.5639 /gabij.2013.0203.034

Copyright @ 2013 Pro Pharma Communications International 